\title{
A randomised, double masked, multicentre clinical trial comparing bimatoprost and timolol for the treatment of glaucoma and ocular hypertension
}

\author{
S M Whitcup, L B Cantor, A M VanDenburgh, K Chen, for the Bimatoprost Study \\ Group II*
}

Br J Ophthalmol 2003;87:57-62

${ }^{*}$ Members are listed in the appendix.

See end of article for authors' affiliations

....................

Correspondence to: Scott M Whitcup, MD, Ophthalmology Clinical Research, Allergan, 2525 Dupont Drive, Irvine, CA 92623-9534 USA:

Whitcup_Scott@allergan.com

Accepted for publication 16 July 2002

\begin{abstract}
Aim: To evaluate the safety and efficacy of bimatoprost $0.03 \%$ once daily or twice daily compared with timolol $0.5 \%$ twice daily in patients with glaucoma or ocular hypertension.

Methods: Multicentre, double masked, randomised, parallel group, 3 month trial comparing bimatoprost once daily $(n=240)$, bimatoprost twice daily $(n=240)$, and timolol twice daily $(n=122)$. The primary efficacy end point was diurnal intraocular pressure (IOP) ( $8 \mathrm{am}, 10 \mathrm{am}, 4 \mathrm{pm}$ ). Safety measures included adverse events, ocular parameters, and systemic variables.

Results: Bimatoprost once daily provided significantly lower mean IOP than timolol twice daily at all times and follow up visits $(p<0.001)$. At month 3, mean IOP reductions from baseline at 10 am (peak timolol effect) were bimatoprost once daily, $8.0 \mathrm{~mm} \mathrm{Hg}(32.4 \%)$; bimatoprost twice daily, $6.3 \mathrm{~mm} \mathrm{Hg}$ (25.2\%); timolol, $5.5 \mathrm{~mm} \mathrm{Hg}(22.7 \%)$. Bimatoprost twice daily was also more effective than timolol, but was not as effective as bimatoprost once daily. A higher percentage of patients achieved low target pressures with bimatoprost once daily than with timolol. The most frequent side effects with bimatoprost were eyelash growth and mild conjunctival hyperaemia. Systemic safety parameters were not affected by bimatoprost.

Conclusions: Bimatoprost $0.03 \%$ once daily demonstrated superior efficacy compared with timolol $0.5 \%$ twice daily in patients with elevated IOP. Bimatoprost once daily was more effective than twice daily dosing.
\end{abstract}

B imatoprost is a member of a new class of agents called prostamides. ${ }^{12}$ Originally described as biosynthetic products of anandamide, ${ }^{3}$ prostamides have been found to effectively lower IOP. ${ }^{2}$ Bimatoprost also profoundly lowers IOP. ${ }^{4}$

The IOP lowering efficacy of bimatoprost has been evaluated in phase II clinical trials. ${ }^{56}$ Bimatoprost $0.03 \%$ once daily or twice daily was significantly more effective than timolol $0.5 \%$ twice daily in lowering IOP in a 1 month clinical evaluation. $^{5}$ A second 1 month trial demonstrated that bimatoprost $0.03 \%$ once daily lowered IOP as well as or better than latanoprost $0.005 \%$ once daily. ${ }^{6}$ In these short term studies, bimatoprost $0.03 \%$ once daily provided mean IOP reductions as large as $8.2 \mathrm{~mm} \mathrm{Hg} \mathrm{(30 \% )} \mathrm{from} \mathrm{baseline} \mathrm{and} \mathrm{was}$ safe and well tolerated.

Two large, multicentre double masked phase III trials were conducted to evaluate the efficacy and safety of bimatoprost as part of Food and Drug Administration registration requirements. The result from one of the phase III studies showed that bimatoprost provided significantly greater IOP lowering than timolol at all follow up time points and visits. In addition, low target pressures were attained in a greater number of patients than in the timolol group. ${ }^{7}$ The data from the phase III study, based on a different patient population, have been presented here. These results demonstrate the superior IOP lowering efficacy of bimatoprost compared to timolol, as was seen in both the other phase III study and the pooled 6 month results. ${ }^{8}$

\section{MATERIALS AND METHODS}

The safety and efficacy of bimatoprost $0.03 \%$ dosed once or twice daily was compared with that of timolol $0.5 \%$ dosed twice daily in a prospective multicentre, double masked, randomised, parallel group, 3 month, clinical trial at 27 centres in the United States and four centres in Canada. The study had a masked extension to 3 years to obtain additional safety and efficacy data. The trial was conducted in compliance with the Declaration of Helsinki, and all investigators obtained appropriate institutional ethics committee or institutional review board approval before initiating the study. All patients provided informed consent before any study related procedures or changes in treatment.

\section{Patients}

The primary inclusion criteria included age $\geqslant 21$ years; diagnosis of glaucoma or ocular hypertension requiring treatment in both eyes; IOP in each eye $\geqslant 22 \mathrm{~mm} \mathrm{Hg}$ and $\leqslant 34 \mathrm{~mm} \mathrm{Hg}$ at $8 \mathrm{am}$ on baseline after washout of any previous antiglaucoma medication; likely to be controlled on monotherapy; best corrected visual acuity $20 / 100$ or better in each eye; and two reliable visual fields collected before dosing. Primary exclusion criteria included any uncontrolled systemic disease; anticipated alteration of ongoing therapy with agents that could have a substantial effect on IOP or interact with study medications or outcomes; required chronic use of ocular medications other than the study medications during the study; functionally significant visual field loss within the past year; clinically relevant low or high heart rate or blood pressure; any contraindication to $\beta$ blocker therapy; pregnant, lactating, or female of childbearing potential not using reliable birth control; filtering surgery within the past 6 months or laser trabeculoplasty or other intraocular or laser surgery within the past 3 months; history of corneal grafts or refractive surgery (for sites performing endothelial cell counts).

\section{Intervention}

At the prestudy visit to determine patient eligibility, patients on ocular hypotensive drugs began an appropriate washout period before the baseline visit; for other patients, at least 2 days 
elapsed between the prestudy and baseline visits. Study visits were at prestudy, baseline (day 0), weeks 2 and 6, and month 3. All visits began between 7 and 9 am in order to minimise the effects of diurnal variations in IOP. On day 0 patients were randomised to one of three treatment groups: bimatoprost $0.03 \%$ once daily, bimatoprost $0.03 \%$ twice daily, or timolol $0.5 \%$ twice daily in a 2:2:1 ratio based on a block size of 5 . The randomisation schedule was generated using the sas (version 6.12 ) procedure PROC PLAN and the printout was stored in a locked cabinet. Study medications were self administered by instillation of one drop in each eye between 7 and 9 am and between 7 and $9 \mathrm{pm}$. In the bimatoprost once daily group, bimatoprost was administered in the evening, and a vehicle solution was administered in the morning. Identically appearing masked bottles were colour coded for use in the morning or evening. On the morning of study visits, personnel at the study centre instilled the masked medication after the eye examinations.

\section{Main outcome measures}

The primary end point was IOP at $8 \mathrm{am}, 10 \mathrm{am}$, and $4 \mathrm{pm}$ at week 2, week 6, and month 3 measured using Goldmann applanation. Two or three measurements were taken for each eye; analyses used data from the eye with the higher IOP at 8 am on day 0. Measurements were performed at 8 am (between 7 and $9 \mathrm{am}$; immediately preceding the morning dose of study medication) and at 2 and 8 hours after the 8 am dose. At selected sites, measurements were also taken at 12 hours after the 8 am dose.

Safety measures were also monitored. Adverse events, biomicroscopy, iris pigmentation, visual acuity, blood pressure, and heart rate were assessed at each study visit. Ophthalmoscopic examinations as well as visual field, haematology, and blood chemistry evaluations were conducted at prestudy and month 3.

The severity of adverse events was assessed using the following definitions as guidelines: mild $=$ awareness of sign or symptom, but easily tolerated; moderate = enough discomfort to cause interference with usual activity; severe = incapacitating with inability to work or do usual activity. To evaluate changes in iris pigmentation, investigator(s) at each site compared Polaroid photographs of patient's eyes from baseline and follow up visits. A colour calibration strip was photographed beside the eye to verify consistent photographic colour processing. A reading centre at the sponsor site (consisting of two evaluators) also evaluated all photographs in a masked fashion and obtained slightly lower but generally comparable results.

\section{Statistical analysis}

Nominal categorical variables were analysed using Fisher's exact test, Pearson's $\chi^{2}$ test, ${ }^{9}$ or Cochran-Mantel-Haenszel methods. ${ }^{10}$ Ordinal categorical variables were analysed with the Wilcoxon rank sum test, ${ }^{11}$ with within group changes from baseline analysed using the Wilcoxon signed rank test. ${ }^{12}$ Continuous variables were analysed using ANOVA, with within group changes from baseline analysed using paired $t$ tests. All randomised patients received at least one dose of the study medication and were included in safety analyses. IOP data with last observation carried forward were analysed for the intent to treat population. For the between group comparisons of IOP, assessed at three time points on study visits at week 2 , week 6, and month 3, a strategy of combined tests of non-inferiority and superiority was performed ${ }^{13}$ with a two sided significance level of 0.05 considered statistically significant. Two sided 95\% confidence intervals (CI) of the differences in mean IOP between each bimatoprost group and the timolol group were calculated using least squares means. In the analysis of IOP at each time point, bimatoprost was deemed superior to timolol when the upper limit of the 95\% CI of the difference (bimatoprost minus timolol) was $<0$, and bimatoprost was not inferior to timolol when the upper limit of the $95 \%$ CI of this difference (bimatoprost minus timolol) was less than a non-inferiority margin (1 $\mathrm{mm} \mathrm{Hg}$ or $1.5 \mathrm{~mm}$ $\mathrm{Hg}$ ). Bimatoprost was claimed to be non-inferior to timolol when ( 1 ) using a non-inferiority margin of $1 \mathrm{~mm} \mathrm{Hg}$, bimatoprost was non-inferior to timolol at a majority of IOP measurements, and (2) using a non-inferiority margin of 1.5 $\mathrm{mm} \mathrm{Hg}$, bimatoprost was non-inferior to timolol at all IOP measurements. Bimatoprost once daily was compared with bimatoprost twice daily using similar tests.

With 200 patients in each bimatoprost group and 100 patients in the timolol group, the power was 0.85 to claim non-inferiority of bimatoprost to timolol based on a noninferiority margin of $1.5 \mathrm{~mm} \mathrm{Hg}$, using a standard deviation of 4.052 , an estimate of variability from a phase II study. ${ }^{5}$

\section{RESULTS}

\section{Patient demographics and disposition}

A total of 602 patients were enrolled: 240 in the bimatoprost once daily group, 240 in the bimatoprost twice daily group, and 122 in the timolol group. There were no significant differences in demographic variables between treatment groups (Table 1). Approximately half of the patients (49.8\%) were diagnosed with glaucoma. The patient population was $76.7 \%$ white, 16.9\% African-American, 5.6\% Hispanic, and 0.7\% other. In general, ophthalmic and medical histories as well as diurnal mean IOP were comparable among treatment groups.

Most patients in each treatment group $(228 / 240,95.0 \%$ in the bimatoprost once daily group; 206/240, $85.8 \%$ in the bimatoprost twice daily group; and 116/122, 95.1\% in the timolol group) completed 3 months of treatment. Few patients discontinued owing to lack of efficacy $(0,0 \%)$ in the bimatoprost once daily group, five $(2.1 \%)$ in the bimatoprost twice daily group, and $1(0.8 \%)$ in the timolol group).

\section{IOP lowering efficacy}

Bimatoprost once daily provided significantly lower mean IOP than timolol twice daily at all times of day and at all follow up visits $(\mathrm{p}<0.001)$. For example, at $10 \mathrm{am}$ (peak timolol effect), mean IOP at month 3 was $16.7 \mathrm{~mm} \mathrm{Hg}$ in the bimatoprost once daily group, $18.6 \mathrm{~mm} \mathrm{Hg}$ in the bimatoprost twice daily group, and $18.6 \mathrm{~mm} \mathrm{Hg}$ in the timolol group (Fig l). At 8 am, mean IOP at month 3 was $17.5 \mathrm{~mm} \mathrm{Hg}$ in the bimatoprost once daily group, $18.8 \mathrm{~mm} \mathrm{Hg}$ in the bimatoprost twice daily group, and $19.6 \mathrm{~mm} \mathrm{Hg}$ in the timolol group.

Bimatoprost once daily also provided significantly greater mean IOP reductions from baseline than did timolol twice daily at all times of day and all follow up visits $(\mathrm{p}<0.001)$. Mean IOP reductions from baseline (at $10 \mathrm{am}$, month 3 ) were $8.0 \mathrm{~mm} \mathrm{Hg}$ (32.4\%) with bimatoprost once daily, $6.3 \mathrm{~mm} \mathrm{Hg}$ (25.2\%) with bimatoprost twice daily, and $5.5 \mathrm{~mm} \mathrm{Hg} \mathrm{(22.7 \% )}$ with timolol. At $8 \mathrm{am}$, mean IOP reductions from baseline were $8.4 \mathrm{~mm} \mathrm{Hg}$ with bimatoprost once daily, $7.3 \mathrm{~mm} \mathrm{Hg}$ with bimatoprost twice daily, and $6.2 \mathrm{~mm} \mathrm{Hg}$ with timolol.

The IOP lowering provided by bimatoprost was consistent throughout the day as well as across all follow up visits. At the month 3 visit, mean IOP at $8 \mathrm{am}, 10$ am, and 4 pm ranged from 16.7 to $17.5 \mathrm{~mm} \mathrm{Hg}$ with bimatoprost once daily, from 18.0 to $18.8 \mathrm{~mm} \mathrm{Hg}$ with bimatoprost twice daily, and from 18.6 to $19.6 \mathrm{~mm} \mathrm{Hg}$ with timolol (Fig 2). The mean IOP reductions provided by bimatoprost once daily were significantly greater than those provided by timolol twice daily at $8 \mathrm{am}, 10 \mathrm{am}$, and $4 \mathrm{pm}$ at all follow up visits $(\mathrm{p}<0.001)$. Mean IOP reductions were consistently greater with once daily than with twice daily dosing of bimatoprost, and the difference between groups was statistically significant at most time points.

Bimatoprost was shown to be non-inferior to timolol, based on the non-inferiority criterion, at all follow up visits. Importantly, the upper limit of the confidence intervals of the 


\begin{tabular}{|c|c|c|c|c|}
\hline & $\begin{array}{l}\text { Bimatoprost once } \\
\text { daily }(n=240)\end{array}$ & $\begin{array}{l}\text { Bimatoprost twice } \\
\text { daily }(n=240)\end{array}$ & Timolol $(n=122)$ & $\mathrm{p}$ Value \\
\hline Mean age (SEM) (years) & $\begin{array}{l}60.3(0.8) \\
\text { (range 22-83) }\end{array}$ & $\begin{array}{l}61.4(0.8) \\
\text { (range 33-90) }\end{array}$ & $\begin{array}{l}60.0(1.1) \\
\text { (range 33-83) }\end{array}$ & 0.459 \\
\hline Sex & & & & 0.623 \\
\hline Male & $108(45.0 \%)$ & $117(48.8 \%)$ & $54(44.3 \%)$ & \\
\hline Female & $132(55.0 \%)$ & $123(51.3 \%)$ & $68(55.7 \%)$ & \\
\hline Race & & & & 0.344 \\
\hline White & $186(77.5 \%)$ & 191 (79.6\%) & $85(69.7 \%)$ & \\
\hline Black & $39(16.3 \%)$ & $37(15.4 \%)$ & $26(21.3 \%)$ & \\
\hline Asian & $0(0.0 \%)$ & $1(0.4 \%)$ & $2(1.6 \%)$ & \\
\hline Hispanic & $15(6.3 \%)$ & $10(4.2 \%)$ & $9(7.4 \%)$ & \\
\hline Other & $0(0.0 \%)$ & $1(0.4 \%)$ & $0(0.0 \%)$ & \\
\hline Iris colour & & & & 0.125 \\
\hline Blue & $69(28.8 \%)$ & $55(22.9 \%)$ & $24(19.7 \%)$ & \\
\hline Brown & $81(33.8 \%)$ & $88(36.7 \%)$ & $53(43.4 \%)$ & \\
\hline Green & $9(3.8 \%)$ & $5(2.1 \%)$ & $7(5.7 \%)$ & \\
\hline Dark brown & $22(9.2 \%)$ & $21(8.8 \%)$ & $13(10.7 \%)$ & \\
\hline Yellow-brown & $31(12.9 \%)$ & $30(12.5 \%)$ & $10(8.2 \%)$ & \\
\hline Grey & $1(0.4 \%)$ & $4(1.7 \%)$ & $0(0.0 \%)$ & \\
\hline Blue-grey & $6(2.5 \%)$ & $10(4.2 \%)$ & $3(2.5 \%)$ & \\
\hline Green-brown & $6(2.5 \%)$ & $6(2.5 \%)$ & $6(4.9 \%)$ & \\
\hline Blue/grey-brown & $11(4.6 \%)$ & $16(6.7 \%)$ & $2(1.6 \%)$ & \\
\hline Other & $4(1.7 \%)$ & $5(2.1 \%)$ & $4(3.3 \%)$ & \\
\hline Diagnosis & & & & 0.407 \\
\hline Glaucoma & $123(51.3 \%)$ & $122(50.8 \%)$ & $55(45.1 \%)$ & \\
\hline $\mathrm{OHT}^{*}$ & 111 (46.3\%) & $108(45.0 \%)$ & $65(53.3 \%)$ & \\
\hline Glaucoma/OHT† & $6(2.5 \%)$ & $10(4.2 \%)$ & $2(1 . \%)$ & \\
\hline Washout required & & & & 0.491 \\
\hline Yes & $146(60.8 \%)$ & $153(63.8 \%)$ & $70(57.4 \%)$ & \\
\hline No & $94(39.2 \%)$ & $87(36.3 \%)$ & $52(42.6 \%)$ & \\
\hline \multicolumn{5}{|c|}{ Mean (SD) IOP at baseline $(\mathrm{mm} \mathrm{Hg})$} \\
\hline $8 \mathrm{am}$ & $25.9(3.2)$ & $26.1(3.1)$ & $25.8(2.9)$ & 0.529 \\
\hline $10 \mathrm{am}$ & $24.6(3.9)$ & $24.8(4.0)$ & $24.0(3.6)$ & 0.232 \\
\hline $4 \mathrm{pm}$ & $23.9(4.0)$ & $23.9(4.2)$ & $23.2(3.9)$ & 0.148 \\
\hline $8 \mathrm{pm} \ddagger$ & $21.4(4.6)(n=39)$ & $22.6(5.0)(n=39)$ & $22.6(4.5)(n=20)$ & 0.608 \\
\hline
\end{tabular}

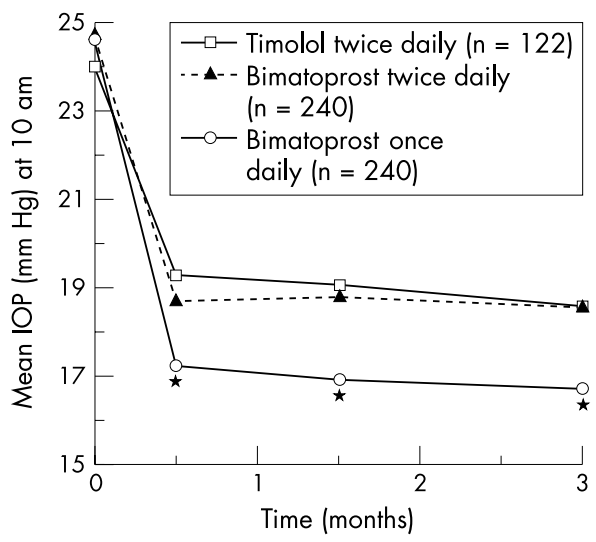

Figure 1 Mean IOP at 10 am at baseline and follow up study visits. Mean IOP with bimatoprost once daily was consistently significantly lower than with timolol or bimatoprost twice daily at follow up visits. ${ }^{*} p<0.001 v$ timolol and bimatoprost twice daily.

bimatoprost minus timolol difference in IOP was less than 0 at all times of day at all follow up visits, demonstrating that bimatoprost once daily was superior to timolol in IOP lowering.

A higher percentage of patients in the bimatoprost groups than in the timolol group achieved low target pressures. Response rates for all target IOPs were highest with the bimatoprost once daily regimen (Fig 3). For example, at $10 \mathrm{am}$ at the month 3 visit, $62.1 \%$ of bimatoprost once daily patients achieved IOP $\leqslant 17 \mathrm{~mm} \mathrm{Hg}$ compared with $31.1 \%$ of timolol patients $(\mathrm{p}<0.001)$. IOP $\leqslant 17 \mathrm{~mm} \mathrm{Hg}$ was achieved by $41.7 \%$ of

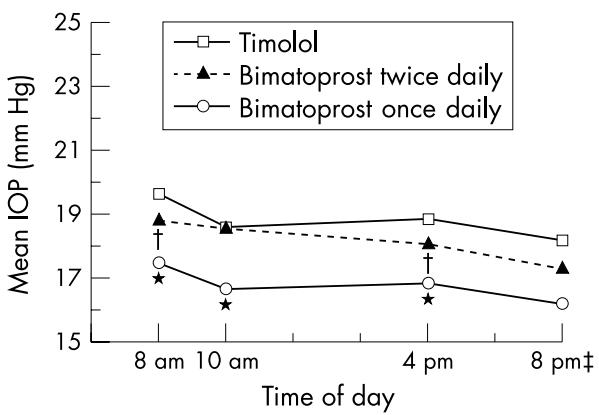

Figure 2 Diurnal mean IOP at month 3. Mean IOP was significantly lower with bimatoprost once daily than with timolol at $8 \mathrm{am}, 10 \mathrm{am}$, and $4 \mathrm{pm}$. Mean IOP in the bimatoprost twice daily group was significantly lower than in the timolol group at 8 am and $4 \mathrm{pm}$. Smaller sample sizes at $8 \mathrm{pm}$ resulted in inadequate power for pairwise statistical comparisons. ${ }^{*} p<0.001 v$ timolol and bimatoprost twice daily; $\nmid p \leqslant 0.048 v$ timolol; $\ddagger$ Only measured at selected sites.

bimatoprost twice daily patients (data not shown). At 8 am, $52.1 \%$ of bimatoprost once daily patients achieved IOP $\leqslant 17$ mm Hg compared with $26.2 \%$ of timolol patients $(p<0.001)$. The bimatoprost once daily regimen was also superior in allowing more patients to achieve large percentage reductions in IOP from baseline (Table 2). For example, at 10 am at month 3 , IOP reductions $\geqslant 35 \%$ from baseline were achieved by $42.10 \%$ of bimatoprost once daily patients compared with $18.0 \%$ of timolol patients $(\mathrm{p}<0.001)$. At 8 am at month 3 , IOP reductions $\geqslant 35 \%$ from baseline were achieved by $43.3 \%$ of 


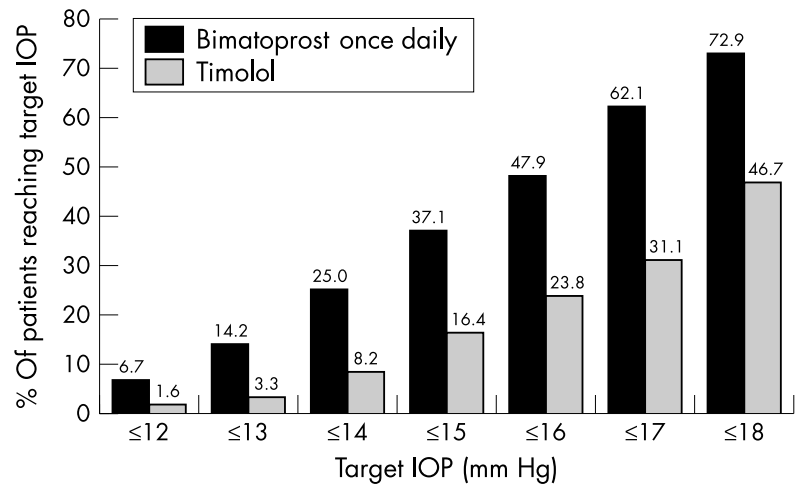

Figure 3 Response rates. The percentage of patients that achieved target IOP levels at $10 \mathrm{am}$ is shown for the month 3 visit.

Table 2 Response rates. The percentage of patients that achieved target $\%$ IOP reductions at 10 am at the month 3 visit is shown

\begin{tabular}{llll}
\hline $\begin{array}{l}\text { Target \% IOP } \\
\text { reduction }\end{array}$ & $\begin{array}{l}\text { Bimatoprost } \\
\text { once daily }\end{array}$ & $\begin{array}{l}\text { Timolol twice } \\
\text { daily }\end{array}$ & p Value \\
\hline$\geqslant 35 \%$ & $42.1 \%$ & $18.0 \%$ & $<0.001$ \\
$\geqslant 30 \%$ & $63.3 \%$ & $32.0 \%$ & $<0.001$ \\
$\geqslant 25 \%$ & $73.8 \%$ & $42.6 \%$ & $<0.001$ \\
$\geqslant 20 \%$ & $84.2 \%$ & $54.9 \%$ & $<0.001$ \\
\hline
\end{tabular}

bimatoprost once daily patients compared with $25.4 \%$ of timolol patients $(\mathrm{p}<0.001)$.

IOP was measured at $8 \mathrm{pm}$ (that is, 24 hours after the last study drug dose in the bimatoprost once daily group and 12 hours after the last dose in the twice daily treatment groups) for a subset of 96 patients. Owing to the small sample sizes in each treatment group, there was inadequate power for non-inferiority tests. However, mean IOP in the bimatoprost once daily group $(n=39)$ at 8 pm ranged from 16.0 to $16.3 \mathrm{~mm}$ $\mathrm{Hg}$ and was consistently approximately $2 \mathrm{~mm} \mathrm{Hg}$ lower than mean IOP in the timolol group (from 18.2 to $18.6 \mathrm{~mm} \mathrm{Hg}$; $\mathrm{n}=20$ ). Mean IOP at $8 \mathrm{pm}$ ranged from 15.7 to $17.2 \mathrm{~mm} \mathrm{Hg}$ with bimatoprost twice daily $(\mathrm{n}=39)$.

\section{Safety measures}

The safety/tolerability profile of bimatoprost once daily was favourable. Treatment related adverse events were mostly mild and were less frequent with once daily than with twice daily dosing of bimatoprost. The most frequent side effects were eyelash growth and conjunctival hyperaemia. Only $6.2 \%$ of bimatoprost once daily patients, $5.8 \%$ of bimatoprost twice daily patients, and $0.9 \%$ timolol patients had a greater than mild ( 1 grade) increase in conjunctival hyperaemia from baseline at the month 3 visit. Mean scores of hyperaemia (worse eye) were in the trace range (from 0.56 to 0.58 during follow up with bimatoprost once daily).

A suspected change in iris pigmentation was reported for one patient $(0.4 \%)$ in the bimatoprost once daily group. There were no significant differences among groups in changes from baseline to month 3 in cup/disc ratio, visual acuity, or visual fields. There were no consistent, clinically significant mean changes from baseline in laser flare meter readings $(n=123)$ or in endothelial cell counts $(n=126)$ in any treatment group.

Heart rate was consistently significantly decreased from baseline only in the timolol group. There were no clinically relevant changes in blood pressure or in urinalysis, haematology, or serum chemistry in any of the treatment groups.

Scatter plots of liver function tests (LFTs) including AST (aspartate aminotransferase), ALT (alanine aminotrans- ferase), and alkaline phosphatase showed no clinically relevant differences between the treatment groups and no clinically significant adverse changes during the course of treatment. Moreover, many patients who entered the study with abnormal LFTs had normal LFTs at 3 months. In the bimatoprost once daily group, 22 of the 26 patients with abnormal LFTs at baseline had results in the normal range at month 3. Thirteen of the 34 patients in the bimatoprost twice daily group that had abnormal LFTs at baseline had normal tests at month 3.

\section{DISCUSSION}

Bimatoprost $0.03 \%$ given once daily in the evening provided statistically significant and clinically relevant IOP lowering superior to timolol twice daily in patients with glaucoma or ocular hypertension. The decreases in IOP achieved with bimatoprost once daily were consistently approximately $2 \mathrm{~mm}$ $\mathrm{Hg}$ greater than those with timolol. The IOP lowering provided by bimatoprost once daily was sustained throughout the day and over 3 months of treatment. Twice daily dosing offered no additional benefit over once daily dosing for lowering IOP.

It is now accepted that IOP lowering efficacy of a medication cannot be evaluated by IOP measurement at a single time point on a single study visit. Regulatory agencies have begun to assess efficacy of glaucoma medications by examining intraocular pressure at several times during the day and on multiple study visits. In this study bimatoprost once daily provided superior IOP lowering compared to timolol at all time points in all study visits. Further, using $95 \%$ confidence intervals of the difference in mean IOP between groups, timolol twice daily was not found to be non-inferior to bimatoprost once daily. Together these analyses show that bimatoprost once daily has IOP lowering efficacy superior to timolol twice daily. This is consistent with the pooled phase III 6 month results as well as the results from the other phase III study. ${ }^{78}$

Several studies have suggested that lowering IOP reduces the risk of glaucoma in patients with elevated IOP. ${ }^{14}{ }^{15}$ Further, for patients with optic disc cupping and visual field loss, reducing IOP clearly lessens the rate of visual field progression. ${ }^{16}{ }^{17}$ For any individual patient, the extent to which IOP should be lowered will depend on multiple factors including the extent of optic nerve damage. ${ }^{18}{ }^{19}$ Target IOP levels in the mid teens or lower are typical for patients with glaucoma. In this study, patients receiving bimatoprost once daily were significantly more likely to achieve target pressures in this range than patients in the timolol group. Furthermore, bimatoprost once daily patients were twice as likely as timolol patients to achieve $\geqslant 35 \%$ reductions in IOP.

Large fluctuations in diurnal IOP are a risk factor for the progression of open angle glaucoma, ${ }^{20}$ and IOP must be controlled throughout the day to minimise optic nerve damage. The results of this trial indicate that bimatoprost provides excellent diurnal IOP control. The flat diurnal curves indicate that bimatoprost effectively controls IOP fluctuations during the day that might predispose the optic nerve to additional damage. ${ }^{20-22}$

Bimatoprost was safe and well tolerated in this trial. Conjunctival hyperaemia was the most commonly reported side effect, but almost $30 \%$ of the patients had conjunctival hyperaemia at baseline and few patients showed more than a mild increase in redness with therapy. Importantly, conjunctival hyperaemia was not associated with intraocular inflammation or other sequelae. In contrast with the decrease in heart rate found in timolol patients, there were no clinically significant effects of bimatoprost on systemic safety parametersincluding liver function tests. The only reported treatment related serious adverse event was acute pulmonary distress in a timolol patient.

In conclusion, in this clinical trial bimatoprost $0.03 \%$ ophthalmic solution was highly efficacious, well tolerated, and 
systemically safe. Bimatoprost given once daily in the evening was statistically and clinically superior to timolol in IOP lowering throughout the day and was more effective than twice daily dosing. Importantly, patients receiving bimatoprost once daily were significantly more likely than timolol patients to achieve substantial IOP reductions and reach low target pressures.

\section{ACKNOWLEDGEMENTS}

This study was sponsored by Allergan, Inc, Irvine, CA, USA. The investigators in the Bimatoprost Study Group II were compensated for their contribution to the study but have no proprietary interests in bimatoprost (Lumigan) or its manufacturer, Allergan, Inc. S Whitcup, A M VanDenburgh, and K Chen are employees of Allergan, Inc.

\section{APPENDIX}

\section{Members of the Bimatoprost Study Group II}

\begin{tabular}{|c|c|c|c|}
\hline Investigators & Subinvestigators & Coordinators/technicians & Sites \\
\hline Allen Beck, MD & Reay Brown, MD, Lynn Harman, MD & Donna Leef & Atlanta, GA, USA \\
\hline Louis Cantor, MD & $\begin{array}{l}\text { Darrell WuDunn, MD, PhD, Alan } \\
\text { Burnstein, MD }\end{array}$ & Jani Hoop, COA, CCRC & Indianapolis, IN, USA \\
\hline George Cioffi, MD & Elizabeth Donohue, MD & Kathryn Sherman & Portland, OR, USA \\
\hline John Cohen, MD & $\begin{array}{l}\text { Michael Parker, OD, Jessica Hildenbrand, } \\
\text { OD }\end{array}$ & Amy Luechaver, COA & Cincinnati, OH, USA \\
\hline David Cooke, MD & $\begin{array}{l}\text { Ronald McKey, MD, David Brown, MD, } \\
\text { Stanley Pletcher, MD, Heath L Lemley, MD }\end{array}$ & Jim Duryee & St Joseph, MI, USA \\
\hline Andrew Crichton, MD & & $\begin{array}{l}\text { Sharon Nugent, Monique Rinke, } \\
\text { Jeannie Reimer }\end{array}$ & Calgary, Alberta, Canada \\
\hline Denise Dudley, MD & $\begin{array}{l}\text { Robin Grendahl, MD, Marvin Grendahl, } \\
\text { MD }\end{array}$ & Gail Leingang, COA & Anchorage, AK, USA \\
\hline Richard Evans, MD & Raymond Hernandez III, MD & Jeff Holland & San Antonio, TX, USA \\
\hline Stephen Greenberg, MD & $\begin{array}{l}\text { Geoffrey Weisman, MD, Michael Weiner, } \\
M D\end{array}$ & Ruthann Burk & Holbrook, NY, USA \\
\hline Ronald Gross, MD & Silvia Orengo-Nania, MD & Pam Frady, COMT, CCRC & Houston, TX, USA \\
\hline Neeru Gupta, MD & & Connie Aitken & Toronto, Ontario, Canada \\
\hline Leonard Gurevich, MD & Jeffrey Calhoun, OD, Philip Sarikey, OD & Iris Miller & West Seneca, NY, USA \\
\hline Oscar Kasner, MD & & & Montréal, Quebec, Canada \\
\hline Donald Kellum, MD & $\begin{array}{l}\text { Donald McCormack, MD, R William Hilty, } \\
\text { MD }\end{array}$ & Denise Munro & Boulder, CO, USA \\
\hline Melvyn Koby, MD & David Karp, MD & Dorothy Jett & Louisville, KY, USA \\
\hline John Kwedar, MD & Randall Peterson, MD & Jennifer Karaffa & Springfield, IL, USA \\
\hline David McGarey, MD & Tomas Tredici, MD & Deann Vest & Flagstaff, AZ, USA \\
\hline Frederick Mikelberg, MD & & & Vancouver, British Columbia, Canada \\
\hline Robert Noecker, MD & Barton Hodes, MD & Luanne Goetsch & Tucson, AZ, USA \\
\hline Leon Remis, MD & & Judy Rodman & Marblehead, MA, USA \\
\hline Robert Ritch, MD & $\begin{array}{l}\text { Jeffrey Liebmann, MD, Robert Rothman, } \\
M D \text {, Celso Tello, MD, Daniel Jewelwicz, } \\
\text { MD, Raghu Mudumbai, MD }\end{array}$ & Ana Norris & New York, NY, USA \\
\hline Michael Rotberg, MD & $\begin{array}{l}\text { George Alter, MD, Andrew Antoszyk, MD, } \\
\text { James Antoszyk, MD, John Bourgeois, MD, } \\
\text { David Browning, MD, Julian Culton, MD, } \\
\text { Robert Flores, MD, Scott Jaben, MD, } \\
\text { Kashyap Kansupada, MD, Timothy } \\
\text { Saunders, MD, Donald Stewart III, MD, } \\
\text { Scott Sutherland, MD, John Weaver, MD, } \\
\text { John Young, MD }\end{array}$ & Julie Lawson & Charlotte, NC, USA \\
\hline Howard Schenker, MD & $\begin{array}{l}\text { Alan Gruber, MD, Paul Hartman, MD, } \\
\text { Ronald Monacelli, OD }\end{array}$ & $\begin{array}{l}\text { Melissa Hart, COA, CCRC, Mindy } \\
\text { Van Voorhis, COT, CCRC }\end{array}$ & Rochester, NY, USA \\
\hline Joel Schuman, MD & & $\begin{array}{l}\text { Mary Anne Beaton, LPN, Kaisha } \\
\text { Rivera, COA }\end{array}$ & Boston, MA, USA \\
\hline Elizabeth Sharpe, MD & William Stewart, MD, David O'Day, MD & Jeanette Stewart & Mt Pleasant, SC, USA \\
\hline Mark Sherwood, MD & $\begin{array}{l}\text { M Fran Smith, MD, J William Doyle, MD, } \\
\text { Michael Morris, MD, David Campbell, } \\
\text { MD, Guy Angella, MD }\end{array}$ & Revonda Burke & Gainesville, FL, USA \\
\hline Joseph Sokol, MD & & Kristen Madigan, COA & Waterbury, CT, USA \\
\hline Alfred Solish, MD & Samuel Solish, MD & Ricki James & Pasadena, CA, USA \\
\hline William Stewart, MD & Elizabeth Sharpe, MD, William Lee, MD & Jeanette Stewart & Charleston, SC USA \\
\hline Julia Whiteside-Michel, MD & Gissur Petursson, MD, Richard Harper, MD & Kelly Overstreet, COA & Little Rock, AR, USA \\
\hline Barbara Wirostko, MD & Richard Davis, MD & & Huntington Station, NY, \\
\hline
\end{tabular}

\section{Authors' affiliations}

S M Whitcup, A M VanDenburgh, K Chen, Allergan, Inc, Irvine, CA, USA

L B Cantor, Department of Ophthalmology, Indiana University School of Medicine, Indianapolis, IN, USA

\section{REFERENCES}

1 Woodward DF, Tang-Liu DD-S, Madhu $C$, et al. Prostaglandin $F_{2}$ $\left(\mathrm{PGF}_{2 \alpha}\right)$ 1-ethanolamide: a pharmacologically unique local hormone biosynthesized from anandamide. 11th International Conference on Advances in Prostaglandin and Leukotriene Research, 2000.

2 Krauss AH-P, Chen J, Protzman C, et al. Pharmacology, biosynthesis and ocular hypotensive activity of prostamide $F_{2 \alpha}$ (prostaglandin $F_{2 \alpha}$ 1 -ethanoloamide), a novel naturally occurring substance. Association for Ocular Pharmacology and Therapeutics, 2000.

3 Yu M, Ives D, Ramesha CS. Synthesis of prostaglandin $E_{2}$ ethanolamide from anandamide by cyclooxygenase-2. J Biol Chem 1997;272:211816.

4 Woodward DF, Krauss AH-P, Chen J, et al. The pharmacology of bimatoprost (Lumigan). Surv Ophthalmol 2001;45(Suppl 4):S337-45.

5 Laibovitz RA, VanDenburgh AM, Felix C, et al. Comparison the ocular hypotensive lipid AGN 192024 with timolol: dosing, efficacy, and safety 
evaluation of a novel compound for glaucoma management. Arch Ophthalmol 2001;119:994-1000.

6 DuBiner H, Cooke D, Dirks $M$, et al. Efficacy and safety of bimatoprost in patients with elevated IOP: a 30-day comparison with latanoprost. Surv Ophthalmol 2001;45(Suppl 4):S353-60.

7 Brandt JD, VanDenburgh AM, Chen K, et al. Comparison of once- or twice-daily bimatoprost with twice-daily timolol in patients with elevated IOP: a 3-month clinical trial. Ophthalmology 2001;108:1023-31.

8 Sherwood M, Brandt J for the Bimatoprost Study Groups 1 and 2. Six-month comparison of bimatoprost once-daily and twice-daily with timolol twice-daily in patients with elevated intraocular pressure. Surv Ophthalmol 2001;45(Suppl 4):S361-8.

9 Agresti A. Categorical data analysis. New York: John Wiley, 1990:47-48, 59-66

10 Landis RJ, Heyman ER, Koch GG. Average partial association in 3-way contingency tables: a review and discussion of alternative tests. Int Stat $\operatorname{Rev}$ 1978;46:237-54.

11 Lehmann EL, D'Abrera HJM. Nonparametrics: statistical methods based on ranks. California: Holden-Day, 1975.

12 Conover WJ, Iman RL. Rank transformations as a bridge between parametric and nonparametric studies. American Statistician 1981;35:124-33.

13 Morikawa T, Yoshida M. A useful testing strategy in phase III trials: combined test of superiority and test of equivalence. J Biopharm Stat 1995;5:297-306.
14 Epstein DL, Krug JH Jr, Hertzmark E, et al. A long-term clinical trial of timolol therapy versus no treatment in the management of glaucoma suspects. Ophthalmology 1989;96:1460-7

15 Kass MA, Gordon MO, Hoff MR, et al. Topical timolol administration reduces the incidence of glaucomatous damage in ocular hypertensive individuals. A randomized, double-masked, long-term clinical trial. Arch Ophthalmol 1989:107:1590-8.

16 Mao LK, Stewart WC, Shields MB. Correlation between intraocular pressure control and progressive glaucomatous damage in primary open-angle glaucoma. Am J Ophthalmol 1991;111:51-5.

17 The Advanced Glaucoma Intervention Study (AGIS): 7. The relationship between control of intraocular pressure and visual field deterioration. The AGIS Investigators. Am J Ophthalmol 2000;130:429-40

18 Zeyen T. Target pressures in glaucoma. Bull Soc Belge Ophtalmol 1999;274:61-5

19 Singh K, Spaeth G, Zimmerman T, et al. Target pressureglaucomatologists' holey grail. Ophthalmology 2000;107:629-30.

20 Asrani S, Zeimer R, Wilensky J, et al. Large diurnal fluctuations in intraocular pressure are an independent risk factor in patients with glaucoma. J Glaucoma 2000;9:134-42.

21 Sacca SC, Rolando M, Marletta A, et al. Fluctuations of intraocular pressure during the day in open-angle glaucoma, normal-tension glaucoma and normal subjects. Ophthalmologica 1998;212:115-19.

22 Zeimer RC, Wilensky JT, Gieser DK. Presence and rapid decline of early morning intraocular pressure peaks in glaucoma patients. Ophthalmology 1990:97:547-50.

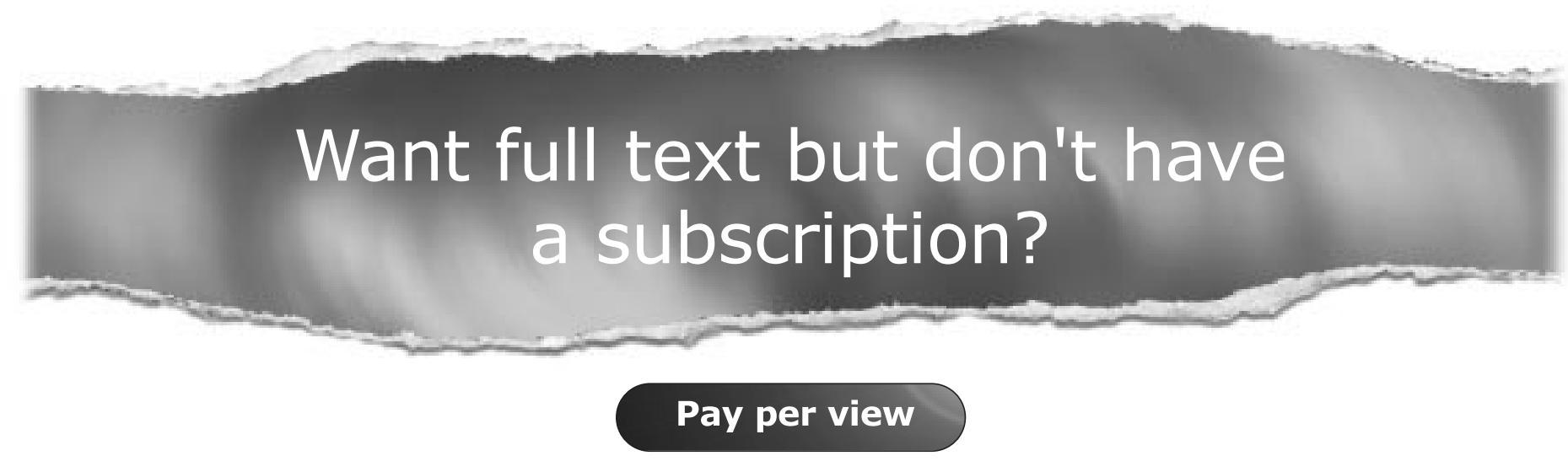

For just \$8 you can purchase the full text of individual articles using our secure online ordering service. You will have access to the full text of the relevant article for 48 hours during which time you may download and print the pdf file for personal use.

\section{www.bjophthalmol.com}

